\title{
A ação humana nos caminhos de Max Weber e Hannah Arendt
}

\author{
Lúcio Alves de Barros ${ }^{1}$ \\ lucba@terra.com.br
}

\begin{abstract}
Resumo
No presente artigo, percorre-se o caminho do conceito de ação em Max Weber e Hannah Arendt. A ação humana aparece como elemento produtor de conhecimento. Aparentemente, a centralidade do conceito segue caminhos diferentes, mas torna-se inquestionável sua importância como ponto de partida e desenvolvimento em suas obras.
\end{abstract}

Palavras-chave: ação; Max Weber; Hannah Arendt.

\section{Introdução}

Não são inéditas as concepções acerca das condições da natureza das motivações humanas. Não é necessário ir tão longe para detectar esta preocupação. Sem mencionar o mundo grego, podemos falar do interessante debate entre os racionalistas e empiristas, os quais, atentos ao dogmatismo da filosofia medieval, vão se debruçar nos temas relativos à razão ou ao império do mundo sensível. Deus, após os acontecimentos que se seguiram às determinações da filosofia escolástica, perdeu a centralidade e a ação racional ganhou vida e vigor.

No artigo a seguir, grosso modo, busca-se deixar claras as concepções de Max Weber e Hannah Arendt no que diz respeito

1 Professor do mestrado em administração da FEAD - BH. Doutor em ciências humanas sociologia e política pela UFMG e organizador do livro "Mulher, política e sociedade" (Ed. ASA, 2009).

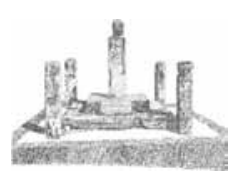


à ação humana; um tema que, mesmo nos dias atuais, ainda causa mal-estar aos estudiosos das ciências humanas.

\section{O ser de ação de Max Weber}

A proposta de Max Weber (1864-1920) no que concerne ao conceito de ação tem como ponto de partida as concepções de Immanuel Kant (1724-1804), o qual, acordado por David Hume de seu "sono dogmático" em meados do século XVIII, praticou uma verdadeira revolução, a qual chamou de "Copernicana". O objetivo de Kant era demonstrar que a razão consistia em um órgão autônomo e eficaz para a conduta humana. Entretanto, regulavase pela natureza dos objetos na construção do conhecimento. Para que este fosse possível, era necessária a existência de um objeto exterior que desencadeasse a ação do pensamento e ao qual todo o conhecimento devia se referir. Além disso, era de fundamental importância a participação do sujeito cognoscente, ou seja, um agente capaz de desenvolver os "imperativos categóricos" presentes no universo mental. Essa capacidade permitia aos indivíduos entender as conexões captadas pelas impressões sensíveis, fornecendo, para isso, algo de sua própria capacidade de conhecer ${ }^{2}$.

As ideias de Kant influenciaram os principais filósofos de Heidelberg, entre eles Wilhelm Windelband (1848-1915) e Heinrich Richert (1863-1936). Outros também se destacam, como Georg Simmel (1858-1918) e o filósofo das "ciências do espírito" Wilhelm Dilthey (1833-1911), todos mais tarde apelidados de neokantianos (BENDIX, 1986; CHACON, 1991).

Max Weber se insere nesse debate, desenvolvido em meados do século XIX, no qual o que estava em jogo era o estatuto das Ciências Sociais. Nesse debate, cumpre apontar sua preocupação com a pesquisa histórico-social de seu tempo e a constituição

2 Para uma abordagem sistemática do assunto, ver a obra do autor: "Crítica da Razão Pura" de 1781. Em Kant. São Paulo: Ed. Abril Cultural, 1983 (Coleção Os Pensadores), especificamente a parte intitulada "Analítica Transcendental". Deve-se conferir também os "Prolegômenos a toda Metafísica futura que possa apresentar-se como ciência" de 1783. Como a obra anterior era considerada de difícil entendimento, Kant escreveu este livro para explicá-la. 
de uma ciência capaz de apreendê-los (MISSE, 2011). Weber tratará de organizar seus escritos numa tentativa explícita de homogeneização e padronização dos conceitos construídos de maneira tipológica. Em relação a esse empreendimento de Weber, Chacon (1991, p. 342) assevera que: "Marx Weber supera o neokantismo e a si mesmo, pelo caminho da pesquisa histórica e sociológica. Aqui é que aparece a grandeza de Economia e Sociedade, culminação de minuciosos levantamentos que ele fazia desde a juventude".

Destacamos, em resumo, os pressupostos epistemológicos da filosofia alemã incorporados por Weber. Entretanto, este era um assíduo leitor dos liberais franceses, nos quais buscou, entre muitas contribuições, a concepção de Estado, mercado, política e, principalmente, a ideia de indivíduo vitalizador de ação (FREUND, 1987). Acreditamos que é na junção dessas concepções que Weber construirá o seu arcabouço teórico.

Partindo do indivíduo como realidade objetiva, Weber reivindicará para as ciências sociais o seu próprio estatuto metodológico. A busca de uma ciência social que entenda os fatos humanos é que estava em questão. O argumento principal é que a ação humana é radicalmente de inspiração subjetiva. $\mathrm{O}$ comportamento humano, ao contrário dos fenômenos naturais, não pode ser descrito e muito menos explicado com base apenas em características exteriores e observáveis, uma vez que o mesmo ato externo pode corresponder a sentidos e ações muito diferentes.

A tentativa de um conhecimento da realidade 'livre de pressupostos' (grifo do autor) apenas conseguiria produzir um caos de 'juízos existenciais' acerca de inúmeras percepções particulares. E mesmo este resultado só na aparência seria possível, já que a realidade de cada uma das percepções, expostas a uma análise detalhada, oferece um sem-número de elementos particulares, que nunca poderão ser expressos de modo exaustivo nos juízos de percepção (WEBER, 1986, p. 94). 
Para Weber, a ciência que se preocupa com o que é humano será inquestionavelmente uma ciência interobjetiva e não há formas de torná-la objetiva conforme apregoam os defensores das ciências naturais. A postura epistemológica das ciências humanas é a de compreensão dos fenômenos sociais a partir das próprias atitudes mentais e do sentido que os agentes conferem às suas ações.

A ciência social que nós pretendemos praticar é uma ciência da realidade. Procuramos compreender a realidade da vida que nos rodeia e na qual nos encontramos situados naquilo que tem de específico; por um lado, as conexões e a significação cultural das suas diversas manifestações na sua configuração atual e, por outro, as causas pelas quais se desenvolveu historicamente assim e não de outro modo (WEBER, 1986, p. 88).

O conceito de ação no contexto delineado é fundamental e o autor o conceitua da seguinte forma:

Por 'acción` debe entenderse una conducta humana (bien consista en un hacer externo o interno, ya en un omitir o permitir) siempre que el sujeto os los sujetos de la acción enlacen a ella un sentido subjetivo. La 'acción social', por tanto, es una acción en donde el sentido mentado por su sujeto o sujetos está referido a la conducta de otros, orientándose por ésta en su desarollo (WEBER, 1964, p.5).

Pode-se perceber que a ação individual para ser social necessita do outro. No entanto, o autor não deixa de mencionar a existência de ações que não necessitam da alteridade. Em função de nosso objetivo, delineamos quais são elas. Weber distingue, grosso modo, dois tipos de ação: a ação racional e a ação irracional. Em cada caso caracteriza dois "subgrupos":

Ação racional com relação a fins, "determinada por expectativas no comportamento tanto de objetos do mundo exterior como de outros homens, e utilizando essas expectativas 
como 'condições' ou 'meios' para alcançar fins próprios e racionalmente avaliados e perseguidos".

Ação racional orientada a valores, "determinada pela crença consciente no valor ético, estético, religioso ou de qualquer outra forma como seja interpretado, próprio e absoluto de determinada conduta, sem relação alguma com o resultado, ou seja, puramente em consideração desse valor".

Ação afetiva, ação irracional emotiva, "determinada por afetos e estados sentimentais". Ação tradicional, "determinada por um costume arraigado" (WEBER, 1964, p. 18-22) ${ }^{3}$.

Infelizmente não sobram linhas para descrever o pensamento desse autor em relação à conexão dessas ações aos conceitos de dominação. Cada ação corresponde a determinados tipos de dominação: a "Dominação Tradicional", "Carismática" e "Legal”.

Atento ao caminho metodológico proposto, Weber ressalta que as formas de dominação são "tipos ideais" apresentados como conceitos definidos e delineados por critérios pessoais. Assim, não são conceitos que podem ser encontrados em sua forma pura na realidade. Para Weber, é possível conseguir aproximações na associação entre o tipo ideal e a realidade.

Mas o que nos interessa é que Weber aposta no sujeito cognoscente, vitalizador de ação e de mudanças estruturais no tecido social. Ao contrário de abordagens holísticas como a de Marx ou de Durkheim, Weber aposta no indivíduo como realidade empírica e analítica. Em Weber somos surpreendidos pelo indivíduo de interesses (materiais e ideais), que manipula os meios para alcançar os fins desejados. Entretanto, trata-se de indivíduos que navegam em hábitos, costumes e tradições. Fatos que interferem na consciência de agentes que podem agir

3 A obra "Economia e Sociedade" é um grande compêndio de conceitos. Weber tinha a intenção de produzir "tipos ideais" construídos sob o olhar do cientista cuidadoso com a intromissão dos "juízos de valor". A estrutura da obra é de difícil - em certos casos - entendimento. Por outro lado, certos conceitos são claros e objetivos. Para melhor entendimento do leitor, optamos por descrevê-los. Para avaliação, ver mais detalhes em Weber (1964, p. 18 a 22). Os grifos são de nossa responsabilidade.

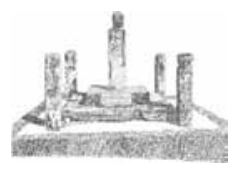


irracionalmente, como é o caso de condutas afetivas e tradicionais. Tal como salienta Freund (1987), em certo sentido, os indivíduos se orientam reciprocamente, pois "sem um mínimo de reciprocidade, não poderia haver relação social nem orientação significativa de um comportamento" (FREUND, 1987, p. 92). Entretanto, são relações, muitas vezes, sem sentido e significado, resultado de estímulos extraordinários.

A ação racional orientada a valores apresenta uma elaboração dos objetivos últimos e o consequente planejamento da ação voltada ao alcance dos objetivos. Todavia, tem em comum (especialmente com a ação afetiva) o fato de colocar o sentido da ação não nos fins, mas na sua própria peculiaridade. Nesse "tipo ideal" de ação, o agente atua por convicções, sejam éticas, estéticas, religiosas ou políticas.

Finalmente, a ação racional orientada a fins é aquela na qual mais se verifica o indivíduo manipulando em prol de seus interesses. $\mathrm{O}$ agente orienta a sua ação pela avaliação racional de fins, meios e consequências implicados nela. Com a finalidade de alcançar os seus objetivos, o ator terá que ponderar racionalmente os meios com os fins, os fins com as consequências implicadas e os diferentes fins possíveis entre si. A decisão entre os vários fins possíveis e as consequências inevitáveis e em conflito pode ser racional orientada a valores. Para Weber, isso dependerá do interesse do ator, que pode ser mais determinante do que a lei, a moral, a tradição ou a ética.

Assim terminamos os tipos de ação elaborados por Weber. Vale frisar que são "tipos ideais" de ação, dos quais os cientistas sociais podem lançar mão para o conhecimento e o ordenamento do fluxo caótico dos acontecimentos. Até porque, é praticamente impossível encontrar de forma pura na realidade a teia de conceitos formulada pelo cientista. Sua utilidade baseia-se por se constituir em um conceito passível de controle, univocidade e parcialidade. Para o autor, essa abordagem permite ao pesquisador detectar as conexões significativas do real, as quais, de uma forma ou de outra, se aproximam do seu quadro conceitual. Em outras palavras, 
são possíveis aproximações no que se refere à compreensão da realidade. Não há como elaborar uma cópia transparente e integral dos dados empíricos. As aproximações, nesse caso, nos permitem a quietude diante de toda ansiedade para conhecer a realidade. Autor atento à construção de conceitos e à problemática da objetividade nas ciências sociais, Weber constrói o conceito de "tipo ideal" que se apresenta em sua teoria da seguinte forma:

Obtém-se um tipo ideal mediante a acentuação unilateral de um ou vários pontos de vista, e mediante o encadeamento de grande quantidade de fenômenos isoladamente dados, difusos e discretos, que se podem dar em maior ou menor número ou mesmo faltar por completo, e que se ordenam segundo os pontos de vista unilateralmente acentuados, a fim de se formar um quadro homogêneo de pensamento. Torna-se impossível encontrar empiricamente na realidade esse quadro, na sua pureza conceitual, pois trata-se de uma utopia (WEBER, 1986, p. 106).

Acentuando as afirmações sobre o tipo ideal e finalizando essa parte, encontramos na mesma obra a seguinte afirmação:

No que se refere à investigação, o conceito do tipo ideal propõe-se formar o juízo de atribuição. Não é uma 'hipótese', mas pretende apontar o caminho para a formação de hipóteses. Embora não constitua uma exposição da realidade, pretende conferir a ela meios expressivos unívocos (WEBER, 1986, p. 106).

\section{A vita activa e a condição humana em Hannah Arendt}

A atividade humana para Hannah Arendt, inspirada no pensamento grego da escola socrática, particularmente em Aristóteles, é dividida em três dimensões consideradas fundamentais no contexto da vita activa: labor (trabalho), work (obra)

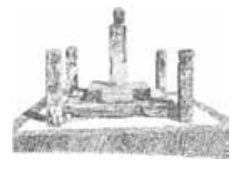


e action (ação). Em "A Condição Humana", o conceito das três dimensões são bem claros e aparecem já em suas páginas iniciais:

$\mathrm{O}$ labor é a atividade que corresponde ao processo biológico do corpo humano, cujos crescimento espontâneo, metabolismo e eventual declínio têm a ver com as necessidades vitais produzidas e introduzidas pelo labor no processo da vida. A condição humana do labor é a própria vida.

O trabalho é a atividade correspondente ao artificialismo da existência humana, existência esta não necessariamente contida no eterno ciclo vital da espécie, e cuja mortalidade não é compensada por este último. $\mathrm{O}$ trabalho produz um mundo artificial de coisas, nitidamente diferente de qualquer ambiente natural. Dentro de suas fronteiras habita cada vida individual, embora esse mundo se destine a sobreviver e a transcender todas as vidas individuais. A condição humana do trabalho é a mundanidade.

A ação, única atividade que se exerce diretamente entre os homens sem a mediação das coisas ou da matéria, corresponde à condição humana da pluralidade, ao fato de que homens, e não o Homem, vivem na Terra e habitam o mundo. Todos os aspectos da condição humana têm alguma relação com a política; mas esta plu $\neg$ ralidade é especificamente a condição - não apenas a conditio sine qua non, mas a conditio per quam - de toda vida política (ARENDT, 1995, p. 15 - grifo nosso).

Em cada dimensão da vita activa encontra-se uma concepção de homem. Respectivamente temos animal laborans, homo faber e animal socialis (zoon politikon). A análise feita dessas esferas é uma clara tentativa de distinguir os três níveis de relações estabelecidas pelos seres humanos com o mundo sensível. Assim, encontramos a relação com a natureza, com os objetos feitos pela mão humana e a relação entre os homens. 
A relação do homem com a natureza é mediada pelo trabalho. Por meio deste, o homem manipula os meios para garantir a vida. $\mathrm{O}$ trabalho aqui diz respeito às atividades corporais que servem não apenas para garantir a vida, mas também a preservação da espécie. O seu resultado são os bens de consumo e suas condições temporais são o da não permanência, ou seja, são produzidos para o consumo humano e, por natureza, são efêmeros. Nesse sentido, trabalho e consumo aparecem de mãos dadas e fazem parte da vida humana com a natureza, pois mesmo que os produtos não sejam de sua propriedade, o seu fim é um só: o retorno à natureza, local de onde saíram.

Arendt destaca que a atividade laboral tem por função básica a preservação da vida. A sobrevivência é um determinante da condição humana e o trabalho é a atividade responsável pela manutenção da vida. O homem, nesse caso, aparece aprisionado ao mundo das necessidades biológicas e, tal como destaca Wanderley Reis (1984), o trabalho humano aparece como

sujeição, condenação ou alienação, como algo de cujo jugo seria necessário ao homem em alguma medida escapar para que possa pretender ascender a uma vida propriamente humana, enquanto distinta da mera sobrevivência animal, e na qual os produtos de sua atividade não estejam desti $\neg$ nados ao desaparecimento imediato através do consumo e de sua incorporação aos processos biológicos ligados à preservação física do indivíduo e da espécie (WANDERLEI REIS, 1984, p. 26).

É justamente nesse sentido que, na cidade antiga, escreve Arendt (1995, p. 94), "trabalhar significava ser escravizado pela necessidade, e esta escravidão era inerente às condições da vida humana". Da análise dessa relação inerente entre necessidade e trabalho, a autora conclui que o uso do termo animal na expressão animal laboral é, de fato, o mais apropriado para esse ser vivo que está sujeito ao mundo das necessidades, pois um ser guiado

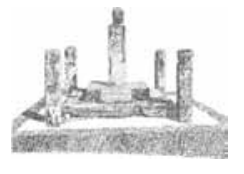


somente pela necessidade não merece ser chamado de homem. Em suas palavras temos: "O animal laborans é, realmente, apenas uma das espécies animais que vivem na terra - na melhor das hipóteses, a mais desenvolvida" (ARENDT, 1995, p. 95).

No que concerne ao homo faber, trata-se do homem que produz obras. Segundo Arendt, o que caracteriza essa atividade é a sua ostensiva permanência entre os homens. A obra produz um mundo artificial e adequado à vida humana. Ao concebê-lo como imagem de sua obra, os homens iniciam sua libertação da necessidade: o que fabricam, os bens de uso são produtos de sua atividade que o colocam em convívio com seus semelhantes. O trabalho humano tem por fundamento a possibilidade de o homem imprimir - tal como também salientou Marx - o seu rosto na natureza. A capacidade de transformar o mundo natural é antecipada por um imaginário mental. O produto é o fim desejado antes em sua mente.

No entanto, Arendt deixa claro que mesmo nessa atividade os seres humanos se veem presos ao mundo da necessidade. Nas obras, é inerente o critério da utilidade que se fundamenta na relação entre meios e fins. Nesse contexto, não há propriamente um fim, haja vista que o objeto acabado, o qual seria o fim do processo de fabricação, tende a tornar-se um meio, ou seja, um mundo estritamente utilitário. Todos os fins tendem a ser de curta durabilidade e a transformarem-se em meios artificiais e distantes das relações humanas.

A última concepção de homem a ser analisada é o animal socialis, o sujeito de ação (práxis). Em largas linhas, refere-se à construção de um mundo comum, no qual os seres humanos são capazes de atingir sua máxima "humanidade". É o mundo da política, do discurso e da ação. Não se refere à esfera das necessidades (labor), da pouca durabilidade das obras e das capacidades humanas que respondem a determinados atributos do animal humano. Ainda nesse sentido, é preciso afirmar que não é produto do raciocínio lógico, tampouco da cognição que emergem um mundo comum, pois para essas funções 
do organismo humano está em questão a efetivação de alguma capacidade humana que corresponde a certas necessidades básicas de sobrevivência e que, por sua vez, são temporais.

No campo da ação, Arendt sustenta que um mundo verdadeiramente humano começa a surgir quando os seres humanos projetam sua força criadora fora das condições objetivas e subjetivas da mera utilidade ou das necessidades vitais. A temporalidade é modificada, e a distinção entre o que permanece e é durável e o que não permanece revela a passagem do mero utilitarismo e necessidade vital para a fundação de um corpo político no qual o não permanente (a vida humana como tal [bios]) é transformado em algo permanente (um mundo comum).

A ação no contexto da vita activa permite que os seres humanos transcendam a mortalidade e a cadeia inexorável de meios e fins. Cadeia que comanda todas as etapas da fabricação e permite que escapem do constrangimento do trabalho imposto pelas necessidades vitais. Nas palavras de Arendt, essa análise aparece da seguinte forma:

Essa distinção singular vem à tona no discurso e na ação. Através deles, os homens podem distinguir-se, ao invés de permanecerem apenas diferentes; a ação e o discurso são os modos pelos quais os seres humanos se manifestam uns aos outros, não como meros objetos físicos, mas enquanto homens. Esta manifestação, em contraposição à mera existência corpórea, depende da iniciativa, mas trata-se de uma iniciativa da qual nenhum ser humano pode abster-se sem deixar de ser humano. Isso não ocorre com nenhuma outra atividade da vita activa (ARENDT, 1995, p. 189).

Dessa forma, fica claro que é na ação e no discurso que cada um dos homens se destaca na espécie. O destaque não se dá por serem homens de razão ou simplesmente seres diferentes dos animais. Sua centralidade e vitalidade cristalizam-se no ser como homem, isto é, como ser que revela a si próprio nos atos e nas palavras.

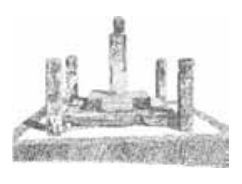


Arendt não está preocupada em revelar se os seres humanos são egoístas ou altruístas. Não parece ser relevante um mundo que não seja paradoxal e, por vezes, imprevisível. Seu objetivo é identificar, ou mesmo recuperar, a atividade perdida sobre os escombros da modernidade, que no passado garantia a humanidade dos seres humanos. É na ação que ela encontra a possibilidade de os seres humanos se transformarem e se colocarem no mundo como tais. A revelação dessa humanidade reside no ato do falar e do agir.

Para Hannah Arendt, a humanidade não se revela no labor ou nas obras. Ela se apresenta com força e vitalidade na identidade inconfundível de cada ser: a capacidade de se apresentar no mundo como humano. Conforme suas palavras:

Os homens podem perfeitamente viver sem trabalhar, obrigando a outros a trabalhar para eles e podem muito bem decidir simplesmente usar e usufruir do mundo das coisas sem lhe acrescentar um só objeto útil; a vida de um explorador ou senhor de escravos ou a vida de um parasita pode ser injusta, mas nem por isto deixa de ser humana. Por outro lado, a vida sem discurso e sem ação - único modo de vida em que há sincera renúncia de toda vaidade e aparência na acepção bíblica da palavra - está literalmente morta para o mundo; deixa de ser uma vida humana, uma vez que já não é vivida entre os homens. É com palavras e atos que nos inserimos no mundo humano; e esta inserção é como um segundo nascimento, no qual confirmamos e assumimos o fato original e singular do nosso aparecimento físico original (ARENDT, 1995, p. 189).

\section{Conclusão}

No artigo em apreço não se tem por objetivo comparar as concepções de ação delineadas por Max Weber e Hannah Arendt. Como se viu, destacamos os principais conceitos que ambos tecem sobre a temática da ação. Na verdade, qualquer trabalho que 
compare Weber e Arendt precisaria de mais fôlego: são autores clássicos, ostensivamente lidos e estudados e imprescindíveis em trabalhos e artigos de respeito. $\mathrm{O}$ artigo, nesse sentido, foi um esforço no intuito de destacar conceitos e mostrar, diante da impossibilidade de reduzir o pensamento dos autores, a temática da ação humana.

A preocupação de Weber sobre o conceito de ação parte de uma postura epistemológica de construção de uma ciência social. Preocupado com os "juízos de valor" e com as abordagens holísticas, notadamente as de conteúdo marxista, chamará atenção para o indivíduo, que aparece em sua obra como principal mecanismo de análise. Em Weber, a ação humana é condicionada por motivações racionais ou irracionais. O ponto de partida está na atitude do agente. O indivíduo é vitalizador de interesses materiais e ideais e, ao seguir suas motivações, encontra as diretrizes para compreender o real.

Hannah Arendt não está preocupada em evidenciar se o homem tem uma natureza altruísta ou utilitária. O que aparentemente lhe interessa é detectar a atividade que humaniza o homem e o perpetua na realidade social. Ao delinear as atividades que compõem a vita activa, destaca três ações fundamentais: trabalho, obra e ação. Esta última permite a humanização do ser. Humanização que se dá pelo discurso e pela práxis comunicativa desenvolvida no espaço público, lugar no qual os homens imprimem suas aspirações e interesses. $\mathrm{O}$ debate de Arendt, influenciado pelo sopro aristotélico da polis, pode ser entendido como uma busca ininterrupta da liberdade política perdida com a emergência e a maturação da modernidade. É na vida pública - diferentemente da esfera privada - que os seres humanos encontram a alteridade, produzindo conflitos e consentimentos, ao mesmo tempo em que encontram campo aberto para a revelação dos interesses e a descoberta da ação das aspirações do outros por meio de atos e palavras.

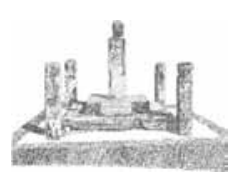




\section{Referências}

ARENDT, H. A Condição Humana. Trad. Roberto Raposo. 7. ed. Rio de Janeiro: Forense Universitária, 1995.

BENDIX, R. Max Weber: um perfil intelectual. Brasília: Ed. UNB, 1986.

CHACON, V. A Encruzilhada de Economia e Sociedade. Revista Humanidades, Brasília, v. 7, n. 4, p. 331-346, 1991.

FREUND, J. Sociologia de Max Weber. Rio de Janeiro: Forense Universitária, 1987.

KANT, I. Crítica da Razão Pura. São Paulo: Abril Cultural, 1983 (Col. Os Pensadores).

MISSE, M. Existe uma sociedade weberiana? Revista CULT, Edição Especial. Os clássicos do Pensamento Social. São Paulo, n. 3, p. 30-32, jan. 2011.

WANDERLEY REIS, F. Política e Racionalidade. Problemas de Teoria e Método de uma Sociologia "Crítica" da Política. Revista Brasileira de Estudos Políticos, Belo Horizonte, UFMG / PROED, 1984.

WEBER, M. A “Objetividade" do Conhecimento nas Ciências Sociais. In: COHN, G. (Org.). Sociologia: Weber. Trad. Amélia Cohn e Gabriel Cohn. 3. ed. São Paulo: Ática, 1986.

. Economia y Sociedad. Esbozo de sociologia comprensiva. México / Buenos Aires: Fondo de Cultura Económica, 1964. . Política como vocação. In: GERTH, H. H.; MILLS, W. (Coord.). Ensaios de Sociologia. 5. ed. Rio de Janeiro: 160 Guanabara, 1982. 


\title{
Human action in the way of Max Weber and Hannah Arendt
}

\begin{abstract}
This paper examines the way of the concept of action in Max Weber and Hannah Arendt. Human action appears as an element of knowledge producer. Apparently, the centrality of the concept follows different paths, but it is unquestionable its importance as a starting point and development in his works.
\end{abstract}

Keywords: action; Max Weber; Hannah Arendt. 